\title{
FAMILY QUALITY OF LIFE IN PRACTICE: A PRACTICAL APPLICATION OF THE FQOL-2006 SURVEY
}

\section{Kierstyn Butler}

\begin{abstract}
As families are increasingly recognized as the primary caregivers for their family members with disabilities, family quality of life (FQOL) research has focused on the impact of disability within the family. This field of research seeks to gain an understanding of the complex challenges and successes families have, with the goal of assisting families in expanding their FQOL. To accomplish this task, the FQOL survey (FQOL-2006) was created. Developed in 2000 and later revised, the FQOL-2006 survey has been used in over 20 countries to explore the perceptions of families, parents, and main caregivers of individuals with intellectual and developmental disabilities. While there has been considerable research using the FQOL-2006 survey, there is limited research that focuses on integrating the survey into practice. This article discusses a possible application of the survey in practical contexts by reflecting on some of the qualitative data collected from my recent FQOL master's thesis study. Specifically, the article highlights the mutual benefits that service providers and families could receive by integrating the FQOL-2006 survey into service models, as it could allow professionals to establish a framework for assessing each client-family's overall quality of life, including their greatest supports, strengths, challenges, and needs. This application provides a new research opportunity for the FQOL field for both researchers and professionals.
\end{abstract}

Keywords: family quality of life, intellectual and developmental disability, FQOL-2006 survey, life transition

Kierstyn Butler MA is a consultant with Children's Autism Services of Edmonton, 7451103 Ave NW, Edmonton, AB T5S 1J4. Email: kierstynbutler@gmail.com 
International Journal of Child, Youth and Family Studies (2018) 9(4): 40-48

One of the ways disability professionals might increase their service's effectiveness is by making an assessment of overall family quality of life (FQOL) to carefully explore and understand the challenges and needs as well as the successes of family and individual life. One such tool is the FQOL-2006 survey, which provides professionals with the ability to better understand their client-family's social, cultural, and community contexts. The FQOL-2006 survey has three key features that support its usefulness as a beneficial service tool. First, it allows families to identify and evaluate areas of family strength and support (e.g., accessible recreation services, family relationships). Second, it allows families to consider and communicate about challenging areas of their life (e.g., limited respite services, underinvestment in siblings' activities). Third, it enables families to discover previously unconsidered facets of their FQOL by encouraging a broader, holistic analysis of the family's well-being. Together, these features of the FQOL-2006 survey can support disability professionals by giving them the knowledge necessary to facilitate more effective practice and services. In this article I will draw on research and my professional experience within the disability sector to argue for the positive contribution that the integration of an FQOL service model, using the FQOL-2006 survey, would provide within disability organizations and services.

\section{Family Quality of Life}

Families are increasingly being recognized as the main caregivers of their family members with disabilities (Knox, 2000); Samuel, Rillotta, \& Brown, 2012). Family members have been taking on increasing roles and responsibilities in caring for their family members with disabilities, and many are in need of assistance from professional and community-based services that address the entire family's welfare. As discussed by Brown and Schippers earlier in this issue, the FQOL framework's adoption of a holistic, family-focused approach enables the identification and amelioration of family challenges that limit members' ability to provide effective and consistent disability support within the family. The field of FQOL research was developed with the aim of assessing families' greatest strengths and greatest challenges in order to determine the conditions that best enable a good FQOL. Towards that end, FQOL research explores family members' perceptions of how disability influences family life for both the individuals and the family unit (Brown \& Brown, 2004). To facilitate improvements in families' quality of life, the FQOL field advocates for family-centered services.

\section{Background Literature}

The concept of FQOL has been applied through the FQOL-2006 survey to various family structures, socioeconomic levels, geographic regions, and time frames. For example, Samuel, Tarraf, and Marsack (2018) evaluated the FQOL-2006's analytical effectiveness by studying the effects of lower socioeconomic status on FQOL. As expected, families with lower socioeconomic status have less access to supportive resources for their children, and thus, their FQOL is relatively low compared with other families. Geography similarly influences the 
International Journal of Child, Youth and Family Studies (2018) 9(4): 40-48

quantity and quality of supportive resources that families may access. The FQOL-2006 survey has, therefore, been translated and applied internationally. For example, Ajuwon and Brown (2012) applied it in Nigeria; Bertelli, Bianco, Rossi, Scuticchio, and Brown (2011) applied it in Italy; and Svraka, Loga, and Brown (2011) applied it in Bosnia and Herzegovina. Lastly, a family's resource needs gradually change across lifespans, affecting both the primary supporters and their family member with a disability. Therefore, research has examined the FQOL of families with children with developmental disabilities (Brown, MacAdam-Crisp, Wang, \& Iarocci, 2006), parents and siblings with a family member with intellectual disability (Werner et al., 2009), and adults with developmental disabilities and their families (Clark, Geake, Smith, Greiner, \& Yost, 2013). Within this literature, however, there is as yet little research that attempts to integrate the FQOL-2006 survey into a practical service model for disability professions - service providers, advocacy organizations, and support programmers.

\section{FQOL-2006 Survey}

What is the FQOL-2006 survey? As described by Isaacs et al. (2007) the International Family Quality of Life Project created the FQOL-2006 survey to provide families with a tool for identifying aspects of their life that are meaningful and supportive; as well, it allows for the identification of areas that are challenging or need to be enhanced, as previously discussed. The survey is lifespan- and culturally-sensitive. It is adaptable and can therefore be applied in several contexts, regardless of the subjects' age, education, family structure, and so on (Giné et al., 2015; Wang \& Brown, 2009). Specifically, the FQOL-2006 survey assesses FQOL across nine domains of family life, including (a) health of the family, (b) financial wellbeing, (c) family relationships, (d) support from other people (e) support from disability-related services, (f) influence of values, (g) careers and preparing for careers, (h) leisure and recreation, and (i) community interaction.

Within each of the nine life domains, six dimensions (or indicators) are used to examine how family members or caregivers perceive their FQOL. These dimensions include (a) importance, (b) opportunity, (c) initiative, (d) stability, (e) attainment, and (f) satisfaction. The survey collects both quantitative and qualitative data on each of the nine life domains using a 5-point Likert scale and with space for open-ended questions. Within this space, families are invited to provide in-depth written responses for each of the nine sections. This research structure gives families the opportunity to clarify or expand on their experiences.

As a practical tool, the FQOL-2006 survey could be mutually beneficial for families and disability professionals, as it provides families with the opportunity to assess the secondary implications of disability within their family's structure. Unlike traditional service frameworks, which individualize care models for family members with disabilities, the FQOL-2006 survey strives to assess how those individuals' service needs are conditioned by and influenced by their families' sociocultural contexts. Concurrently, it provides professionals with a framework for 
International Journal of Child, Youth and Family Studies (2018) 9(4): 40-48

assessing how a family's disability service needs are partially determined by such external factors as limited access to public transportation networks or educational opportunities. Moreover, it seeks to identify how disability service needs influence other family relations or commitments, for example, a sibling's access to recreational programming. With such information, service providers could allocate resources to non-disability factors that affect the family's needs, thereby ameliorating other challenges within their FQOL matrix. Lastly, various service providers or community groups could coordinate their resources to develop a comprehensive care model for the family to bring together previously isolated supports.

\section{Practical Survey Results}

To demonstrate some of the qualitative results produced by the FQOL-2006 survey, I will draw from my recent master's research (Butler, 2017) at the University of Victoria's School of Child and Youth Care. In it, I examined the FQOL of parents and caregivers of individuals with intellectual and developmental disabilities who were transitioning from youth to adult disability services. Although this research involved a small sample of 10 families, the excerpts below from the study's qualitative results help to illustrate the type of information gained and its potential value for professionals in the disability and allied fields.

All families have areas of strength; however, they often struggle to recognize these areas or the social and community resources that support such strengths. The FQOL-2006 survey draws families' attention to these areas by providing an opportunity to reflect on what the family does well, what supports they have, where they are resilient, and what coping methods they apply. Many families commented on the positive aspects of their FQOL. As one participant wrote:

Activism equals empowerment and a sense of control. It also connects you with other families, which reduces isolation and builds connections and the sense you are part of a larger community.

In addition to assisting families in recognizing their strengths, the FQOL survey can provide families with an avenue for exploring how strengths are interconnected - how strengths enable strengths. As one participant wrote: "With supportive caregivers, we are bringing the level of responsibility to where we would like." That is, consistent and stable access to service providers, such as group homes and day programs, enable parents and guardians of adult individuals with disabilities to allocate some responsibilities to others - career skills development, public transportation awareness, recreational training, and so on. Once these services are in place, parents and guardians can reallocate time to previously underserved or unaddressed responsibilities and opportunities.

As well as identifying strengths, the FQOL-2006 survey assists families in identifying challenges, that is, areas where they need the most support or where they experience an imbalance. For example, one of my participants wrote, "As our son needs constant supervision, it 
International Journal of Child, Youth and Family Studies (2018) 9(4): 40-48

is almost impossible to have a regular exercise routine for myself", while another stated, "We are able to participate [in recreation and leisure activities]." Between these comments, we can observe that although some families are able to participate in recreational activities, for instance, those commitments have opportunity costs. Prioritizing one commitment means another goes unrealized. Because disability care is essential, those opportunity costs are often paid by foregoing other personal commitments. As one research participant wrote, "It is usually time and energy on paperwork [and] caregiving that doesn't allow for everyone's needs to be met." Here, we observe how the survey assists families in recognizing and voicing the challenges their family is facing, and how it allows them to pinpoint the barriers to their family's well-being. With this information, service providers can begin to develop a service plan that addresses the challenges, prioritizing those with the greatest impact and the most tangible resolutions.

As with strengths, challenges are often difficult for families to identify. For instance, one survey participant stated, "With several years of dialogue, research, and advocacy, I have located programs and services that [my child] attends and enjoys." In this comment, the participant has highlighted a current strength, the daughter's access to compatible programming. But within this comment there is the challenge of locating those services over several years. This trend of parents and guardians struggling to locate services that fulfil their family member's unique needs could be ameliorated through a practical application of the FQOL-2006 survey. While parents and guardians often cycle through various services and programs to assess their compatibility with the family member's unique disability needs, this cycle is also influenced by non-disability factors, such as location, costs, and scheduling. By encompassing the entire family's needs, the FQOL-2006 survey could help mitigate such challenges by identifying and resolving potential conflicts.

\section{Benefits for Service Providers}

Developing effective services and supports for families requires input from both professionals and families (Blue-Banning, Summers, Frankland, Nelson, \& Beegle, 2004). Professionals bring experience and knowledge of their field, whereas families are the experts on their family's strengths and needs. Together, they can build supportive relationships, create common goals, and develop plans to enhance each family's FQOL (Gatmaitan \& Brown, 2016; Robinson, McInnis, Clark, Duncan, \& Henderson, 2013). However, families are unique: no two families have the same dynamics, values, beliefs, expectations, and priorities. Therefore, it is critically important that the professionals understand, as best they can, their client-family's sociocultural context before developing a care plan.

The FQOL-2006 survey provides practitioners with a framework for engaging in dialogue with families. From the picture created by this dialogue, practitioners can develop an informed care plan that prioritizes the tangible solutions to key challenges by leveraging areas of strength. For example, one family in my study said, "We are lucky enough to have access to waterfront recreational property, which has acted as a family bonding experience." Practitioners 
International Journal of Child, Youth and Family Studies (2018) 9(4): 40-48

could make use of this positive resource by integrating it into other goals, such as recreation or nature education.

The FQOL-2006 survey can reveal the challenges some families are facing. One research participant wrote, "We are tired. We must keep working to provide for our son. We must keep him at home, so our ability to interact with adults our age (empty nesters) is limited." In this comment, the family appears to be struggling with maintaining in-home disability care as they age. Specifically, the continuous care requirement creates a barrier to socializing with peers. Their family could benefit from support and services, such as respite or other housing options, which would support the primary supporters and, thereby, improve the entire family's quality of life (QOL).

Some practitioners will encounter challenges that exceed their organization's mandate. For example, one research participant commented:

We would benefit from more support from the community (i.e., natural support such as friends and neighbours). Also, it would be wonderful to have some intense guidance around developing our son's skill set to lead to eventual semiindependence (at the very least).

Service providers likely cannot help this family develop better rapport with their natural friends and neighbours to create additional support options. However, practitioners could address the ancillary challenges of career development and self-help and independence; that may, in turn, reduce the family's need for those supports. Also, practitioners could direct the family to support groups or family-based programming within the disability community to encourage additional friendships that are grounded within a shared experience.

The current FQOL-2006 survey focuses on families with members who have intellectual and developmental disabilities. However, the essential holistic notion of FQOL is not restricted to those types of disabilities or even disability itself. Practitioners in related human services fields could use the FQOL-2006 survey to assess how physical disabilities or age-related medical conditions influence FQOL. Hopefully, other researchers will undertake such possibilities to further expand the FQOL field, both in theory and in practice.

Altogether, a deeper understanding of their client-families' sociocultural contexts could enable service providers to respond more effectively to each family's unique needs by leveraging strengths, exploring challenges, and reallocating resources. By supporting families as the primary care providers, disability professionals can increase quality of care for the individual with disabilities, since such support will improve the families' overall QOL.

\section{Practical Limitations of the FQOL-2006 Survey}

Although the FQOL-2006 survey provides many benefits for both families and practitioners, the survey has practical limitations for organizations, primarily due to its 
International Journal of Child, Youth and Family Studies (2018) 9(4): 40-48

comprehensiveness. The survey is long and therefore time-consuming for both families and service providers. This is especially true when the survey is conducted face-to-face, an option that may be necessary for families with language barriers or where follow-up interviews are required. Retrieving information from families this way may exceed an organization's financial resources. Furthermore, some families may be unable to complete the survey thoroughly, or families may find the effort and time necessary to complete the survey too burdensome.

To resolve these potential limitations, service providers may prefer to use a shortened version of the survey. Researchers expanding the FQOL field into this potential practical application should be encouraged to develop a shortened version to correspond with their studies' evaluative structures. Toward this end, they may look to supplementary FQOL research to determine which dimensions could be removed or modified while still obtaining sufficiently in-depth information to improve supports for families. As Wang and Brown (2009) suggested, the domains and indicators could be used to shape questions during initial interviews or general conversations with families. Of course, the survey's modifications would differ between different human services sectors, organizations, and regions.

\section{Conclusion}

Families are the primary care providers for individuals with disabilities or related challenges, and therefore, increasing the family's overall QOL will correspondingly improve the quality of primary disability care. As family members' roles and responsibilities as caregivers increase, their need for support necessarily increases as well. To be effective, disability professionals must assist families in creating a resilient foundation for supporting their family members with disabilities. Families should "function as a unit" (Wang \& Brown, 2009, p. 150) insofar as disability care should be mutually accommodating with the family's other commitments and responsibilities. By developing a practical FQOL-2006 survey, disability professionals will gain a holistic care model that accounts for the family's strengths and challenges. Through this information, they will likely find opportunities for increasing the efficiency and effectiveness of disability care. This should strengthen families' FQOL which will in turn strengthen the quality of care for individuals with disabilities. This possibility constitutes a new avenue for the FQOL field and a practical application of the FQOL-2006 survey. 
International Journal of Child, Youth and Family Studies (2018) 9(4): 40-48

\section{References}

Ajuwon, P. M., \& Brown, I. (2012). Family quality of life in Nigeria. Journal of Intellectual Disability Research, 56(1), 61-70. doi:10.1111/j.1365-2788.2011.01487.x

Bertelli, M., Bianco, A., Rossi, M., Scuticchio, D., \& Brown, I. (2011). Relationship between individual quality of life and family quality of life for people with intellectual disability living in Italy. Journal of Intellectual Disability Research, 55(12), 1136-1150. doi:10.1111/j.1365-2788.2011.01464.x

Blue-Banning, M., Summers, J. A., Frankland, H. C., Nelson, L. L., \& Beegle, G. (2004). Dimensions of family and professional partnerships: Constructive guidelines for collaboration. Exceptional Children, 70(2), 167-184. doi:10.1177/001440290407000203

Brown, I., \& Brown, R. I. (2004). Family quality of life as an area of study. In A. Turnbull, I. Brown, \& H. R., Turnbull (Eds.), Families and persons with mental retardation and quality of life: International perspectives (pp. 3-10). Washington, DC: American Association on Intellectual and Developmental Disabilities.

Brown, R. I., MacAdam-Crisp, J., Wang, M., \& Iarocci, G. (2006). Family quality of life when there is a child with a developmental disability. Journal of Policy and Practice in Intellectual Disabilities, 3(4), 238-245. doi:10.1111/j.1741-1130.2006.00085.x

Butler, K. (2017). Eighteen and Up: Researching disability and family quality of life in transition. (Unpublished master's thesis). University of Victoria, Victoria, BC.

Clark, M., Geake, R., Smith, A. D., Greiner, M., \& Yost, E. (2013). The quality of life of adults with developmental disabilities and their families in Calgary Canada: A pilot study. International Journal of Social Science and Humanity, 3(3), 296-299. doi:10.7763/IJSSH.2013.V3.248

Gatmaitan, M., \& Brown, T. (2016). Quality in individualized family service plans: Guidelines for practitioners, programs, and families. Young Exceptional Children, 19(2), 14-32. doi: $10.1177 / 1096250614566540$

Giné, C., Gràcia, M., Vilaseca, R., Salvador Beltran, F., Balcells-Balcells, A., Dalmau Montalà, M., .. \& \& Mas Mestre, J. M. (2015). Family quality of life for people with intellectual disabilities in Catalonia. Journal of Policy and Practice in Intellectual Disabilities, 12(4), 244-254. doi:10.1111/jppi.12134

Isaacs, B. J., Brown, I., Brown, R. I., Baum, N., Myerscough, T., Neikrug, S., ... \& Wang, M. (2007). The international family quality of life project: Goals and description of a survey tool. Journal of Policy and Practice in Intellectual Disabilities, 4(3), 177-185. doi:10.1111/j.1741-1130.2007.00116.x 
International Journal of Child, Youth and Family Studies (2018) 9(4): 40-48

Knox, M. (2000). Family control: The views of families who have a child with a intellectual disability. Journal of Applied Research in Intellectual Disabilities, 13(1), 17-28. doi:10.1046/j.1468-3148.2000.00001.x

Robinson, S., McInnis, B., Clark, J., Duncan, T., \& Henderson, R. (2013). Planning for success: How to write an effective Individualized Service Plan for FSCD. Calgary, AB: Mount Royal University, Alberta Government. Retrieved from http://www.pbsc.info/ISP/manual/isp_manual.pdf

Samuel, P. S., Rillotta, F., \& Brown, I. (2012). Review: The development of family quality of life concepts and measures. Journal of Intellectual Disability Research, 56(1), 1-16. doi:10.1111/j.1365-2788.2011.01486.x

Samuel, P. S., Tarraf, W., \& Marsack, C. (2018). Family quality of life survey (FQOLs-2006): Evaluation of internal consistency, construct, and criterion validity for socioeconomically disadvantaged families. Physical and Occupational Therapy in Pediatrics, (38)1, 46-63. doi:10.1080/01942638.2017.1311393

Svraka, E., Loga, S., \& Brown, I. (2011). Family quality of life: Adult school children with intellectual disabilities in Bosnia and Herzegovina. Journal of Individual Disability Research, (55)12, 1115-1122. doi:10.1111/j.1365-2788.2011.01434.x

Wang, M., \& Brown, R. (2009). Family quality of life: A framework for policy and social service provisions to support families of children with disabilities. Journal of Family Social Work, 12(2), 144-167. doi:10.1080/10522150902874842

Werner, S., Edwards, M., Baum, N., Brown, I., Brown, R. I., \& Isaacs, B. J. (2009). Family quality of life among families with a member who has an intellectual disability: an exploratory examination of key domains and dimensions of the revised FQOL Survey. Journal of Intellectual Disability Research, 53(6), 501-511. doi:10.1111/j.1365$\underline{2788.2009 .01164 . x}$ 